\title{
Núcleos de estudos afro-brasileiros: duas propostas sobre descolonizar a aprendizagem
}

\author{
Sônia Beatriz dos Santos' \\ Joselina da Silva²
}

\begin{abstract}
RESUMO
O presente artigo busca refletir, sob uma perspectiva decolonial, sobre duas experiências de educação antirracista desenvolvidas no Núcleo de Estudos AfroBrasileiros da Universidade do Estado do Rio de Janeiro (NEAB-UERJ) e no Núcleo Brasileiro, Latino Americano e Caribenho de Estudos em Relações Raciais, Gênero e Movimentos Sociais da Universidade Federal Rural do Rio de Janeiro (N'BLAC-UFRRJ). Ambas as propostas buscam se afirmar enquanto projetos acadêmicos e práticas de intervenção do modelo de formação de professoras(es) que se alicerça nas experiências étnico-raciais, culturais e de gênero dos afrodescendentes no Brasil, um modelo que contribui para desconstruir currículos ocultos de estigmatização, marginalização e desumanização das pessoas negras na sociedade.
\end{abstract}

Palavras-chave: Educação decolonial. Decolonialidade. Perspectiva negra. NEABs.

\section{Centers for afro-brazilian studies: two proposals on the decolonization of learning}

\begin{abstract}
The present article seeks to reflect from a decolonial perspective on two experiences of anti-racist education developed at the Center for Afro-Brazilian Studies of the State University of Rio de Janeiro (NEAB-UERJ) and at the Latin American, Caribbean, and Brazilian Center for Racial Relations, Gender, and Social Movement Studies of the Federal Rural University of Rio de Janeiro (N'BLAC-UFRRJ). Both proposals seek to affirm as academic projects and intervention practices of the teacher training models based on the ethnic-racial, cultural, and gender experiences of Afrodescendants in Brazil, which contributes to deconstructing hidden curricula of stigmatization, marginalization and dehumanization of Blacks in society.
\end{abstract}

Keywords: Decolonial education. Decoloniality. Black perspective. NEABs.

\footnotetext{
1 Ph.D. em Antropologia pela Universidade do Texas em Austin, EUA. Professora Adjunta da Universidade do Estado do Rio de Janeiro (UERJ), Rio de Janeiro, Rio de Janeiro, Brasil. Orcid iD: https://orcid.org/0000-0002-4354-5954.E-mail: soniabsantos@yahoo.com

2 Doutora em Ciências Sociais pela Universidade do Estado do Rio de Janeiro (UERJ). Professora Associada da Universidade Federal Rural do Rio de Janeiro (UFRRJ), Seropédica, Rio de Janeiro, Brasil. Orcid iD: https://orcid.org/0000-0002-5159-9055. E-mail: joselinajo@yahoo.com.br
} 


\section{Núcleos de estudios afrobrasileños: dos propuestas sobre descolonizar el aprendizaje}

\section{RESUMEN}

El presente artículo busca reflexionar sobre dos experiencias de educación antirracista bajo una perspectiva decolonial desarrolladas en el Núcleo de Estudios Afrobrasileños de la Universidad del Estado de Río de Janeiro (NEAB-UERJ) y en el N'BLAC - Núcleo Brasileño Latinoamericano y Caribeño de Estudios en Relaciones Raciales, Género y Movimientos Sociales de la UFRRJ - Universidad Federal Rural de Río de Janeiro. Ambas propuestas buscan afirmarse como proyectos académicos y prácticas de intervención del modelo de formación de profesoras que se fundamenta en las experiencias étnico-raciales y culturales, y de género de los afrodescendientes en Brasil, y que contribuya a deconstruir currículos ocultos de estigmatización, marginalización y deshumanización de los negros en la sociedad.

Palabras clave: Educación decolonial. Decolonialidad. Perspectiva negra. NEABs.

\section{Introdução}

A rejeição institucionalizada da diferença é uma necessidade absoluta em uma economia voltada para o lucro, que precisa de forasteiros para compor um excedente de pessoas. Como membros de uma economia desse tipo, fomos todos programados para reagir às diferenças humanas entre nós com medo e desprezo, e para lidar com elas em uma destas três maneiras: não fazer caso delas e, se isso não for possível, copiá-las se as julgarmos dominantes ou destruí-las se as considerarmos subordinadas. Mas não possuímos critérios para nos relacionar como iguais através de nossas diferenças humanas. Em consequência, essas diferenças foram rotuladas e empregadas erroneamente, no interesse da separação e confusão (LORDE, 1984, p. 115, apud WEST, 1994, p. 79).

Transformados em sujeitos coloniais inferiorizados da modernidade, os povos africanos e seus descendentes nas Américas não aceitaram passivamente as tentativas de reinvenção, classificação e subalternização de suas existências, histórias e culturas: desde o processo de colonização iniciado no século XV até os dias atuais, estiveram empenhados em lidar com os discursos e práticas hegemônicos eurocêntricos. Nesse sentido, a educação tem se constituído, sem dúvida, num lócus de empreendimentos acadêmicos e de práticas de oposição e intervenção para garantir a 
integração e as condições materiais de existência das pessoas negras nas sociedades ocidentais, sobretudo naquelas de perspectivas eurocêntricas.

Após realizar um profícuo sobrevoo sobre as diversas teorias pedagógicas - desde as escolanovistas (século XIX), as tecnicistas (meados do século XX), as crítico-reprodutivistas até as teorias sobre os currículos -, Candida Costa (2012) lembra o intenso diálogo entre lugares, épocas, professores e professoras ali estabelecidos. Em outras palavras, para pensarmos um currículo, devemos ter em conta o contexto no qual ele é elaborado, uma vez que seu conteúdo se radica na fluidez de seu tempo e na pertinência com o momento sócio-histórico no qual é constituído.

É evidente que o currículo escolar, enquanto produto da ação humana, não se encontra imune aos interesses sociais, históricos e geograficamente situados. Seu entendimento sob essa perspectiva implica compreender, ao mesmo tempo, que as finalidades da educação escolar também estão implicadas por esses mesmos interesses, de modo que as diferentes teorias de currículo efetuam não somente deslocamentos importantes na maneira como se concebe o currículo nas diferentes épocas, assim como, igualmente, nas finalidades projetadas para a educação (COSTA, 2012, p. 288).

No âmbito das relações étnico-raciais no Brasil, é notória a influência do movimento social negro em parceria com diferentes agentes (autoridades públicas constituídas, discentes, docentes e atores educacionais em diferentes esferas) na produção de um currículo com uma epistemologia no caminho de uma educação antirracista. Como afirma Nilma Gomes (2017), esse movimento é um "educador da sociedade".

Assim, considerando a relevância de projetos que se constituem em pontos de referência e reflexão acerca dos contextos de lutas dos afrodescendentes em distintas realidades da diáspora negra, sobretudo no que se refere à promoção de uma educação contra-hegemônica à dominação europeia, este artigo busca refletir, sob uma perspectiva decolonial, sobre duas experiências de educação antirracista desenvolvidas no Núcleo de Estudos Afro-Brasileiros da Universidade do Estado do Rio de Janeiro (NEAB-UERJ) e no Núcleo Brasileiro, Latino Americano e Caribenho de 
Estudos em Relações Raciais, Gênero e Movimentos Sociais da Universidade Federal Rural do Rio de Janeiro (N'BLAC-UFRRJ). Essas propostas pretendem se afirmar enquanto projeto acadêmico e prática de intervenção do modelo de formação de professoras(es) que se assenta nas experiências étnico-raciais, culturais e de gênero dos afrodescendentes no Brasil, contribuindo para desconstruir currículos ocultos de estigmatização, marginalização e desumanização da população negra na sociedade.

As duas experiências relatadas no trabalho ocorrem no espaço de dois núcleos, O NEAB-UERJ e o N'BLAC-UFRRJ. Assim, iniciaremos a reflexão contextualizando a emergência de tais núcleos no contexto educacional brasileiro.

Num sentido amplo, os NEABs têm por objetivo

promover o fortalecimento da luta e resistência, valorizar a população negra, garantir e ampliar direitos por meio de iniciativas acadêmicas que orientem a formulação de políticas voltadas para a erradicação do racismo e da discriminação (MARQUES; SILVA, 2016, p. 5).

Segundo Marques e Silva (2016), há atualmente 72 núcleos vinculados a instituições de ensino superior no país.

O grande mentor dos NEABs, e posteriormente NEABIs (que passam a incluir os indígenas), foi indubitavelmente o professor e historiador Ubiratan Castro de Araújo (1948-2013), durante sua atuação como presidente da Fundação Cultural Palmares, quando tomou para si a tarefa de incentivar professores universitários a fundar - em parceria com o movimento social núcleos nos quais as questões relativas à população negra fossem estudadas. Assim, Ubiratan Araújo organizou reuniões em várias capitais com o propósito de efetivar a realização dos núcleos.

No Rio de Janeiro, apoiado pela então representante do órgão federal no estado, Elizabeth Viana, o professor convidou inúmeros interessados para uma reunião - hoje considerada histórica - num dos auditórios da Universidade do Estado do Rio de Janeiro (UERJ), no campus Maracanã. No encontro estiveram estudantes, professores e ativistas, 
reunidos inicialmente sem muito consenso acerca da proposta do professor Ubiratan. Alguns dos presentes argumentavam ser aquela uma proposta elitista, por abranger com ênfase o lócus acadêmico, onde os referidos núcleos deveriam ser implementados. Hoje, temos o CONNEABS (Consórcio Nacional dos Núcleos de Estudos Afro-Brasileiros) atuando em universidades públicas e privadas e em escolas de ensino médio e fundamental3.

Gomes e Silva (2011, p. 18) corroboram o fato de que é fundamental discutir com as(os) formandas(os) em Educação que "ao planejar, desencadear e avaliar processos educativos e formadores, não podemos considerar a diferença como estigma". Portanto, urge discutir a questão da diferença à luz do racismo e do preconceito e discriminação raciais que ele gera, num esforço de minimizar e/ou erradicar os efeitos das injustiças e desigualdades raciais contra os povos afrodescendentes. Como enfatizam as autoras, a diferença "é mais um constituinte do nosso processo de humanização. Por meio dela, nós nos tornamos partícipes do processo da formação humana" (GOMES; SILVA, 2011, p.18).

É nesse sentido que buscaremos refletir neste artigo sobre as experiências de educação antirracista desenvolvidas no NEAB-UERJ e no N'BLAC. O artigo está dividido em duas partes. Iniciamos com uma breve reflexão sobre a ideia de uma educação decolonial como uma competência político-pedagógica. Em seguida, expomos duas experiências sobre descolonização dos saberes pautadas nos projetos educacionais antirracistas desenvolvidos nos dois núcleos. Para concluir, tecemos algumas considerações finais.

\footnotetext{
${ }^{3}$ Relato obtido a partir de conversas com a Profa. Dra. Maria Alice Rezende Gonçalves, coordenadora e cofundadora do NEAB-UERJ (2018).
} 


\section{A educação antirracista decolonial ${ }^{4}$ como uma competência político- pedagógica}

O fato de as histórias e culturas africanas e afrodescendentes não serem consideradas relevantes para o currículo da educação básica e da educação superior no Brasil tem como um dos resultados o encobrimento e a desvalorização de seus conhecimentos e saberes; em outros termos, suas cosmologias, mitologias, filosofias, artes, epistemologias e ciências. Tal desvalor é mantido pelo fato de que esses legados não são considerados patrimônio cultural, entendido "como o conjunto de elementos da cultura que é valorizado como bem a ser preservado e ensinado" (CARRARA; CARVALHO; LIMA, 2010, p. 6). E sabemos que a escolha do que será considerado patrimônio cultural, e assim transmitido às gerações futuras através de processos educativos diversos, "se dá por meio de disputas simbólicas que definem quais aspectos da cultura são ou não considerados como patrimônio" (CARRARA; CARVALHO; LIMA, 2010, p. 6). Portanto, é fundamental percebermos que,

[...] ao se propiciarem situações de aprendizagem que levem em conta o patrimônio cultural, criam-se possibilidades de contato com formas diferenciadas de se relacionar com o mundo, favorecendo-se a valorização da diversidade cultural existente e ampliando-se o acesso às manifestações e práticas culturais, aprendizagens cuja construção sinaliza 0 enfrentamento das desigualdades de acesso à cultura, assim como de suas hierarquizações (CARRARA; CARVALHO; LIMA, 2010, p. 1).

Ao pensarmos a organização de um projeto de educação antirracista decolonial nos moldes de um empreendimento acadêmico e da prática de

\footnotetext{
4 Ressaltamos que os termos "decolonialidade"/"decolonial" e "descolonização"/ "descolonizar" têm significados distintos. Descolonização refere-se, em termos históricos e temporais, ao processo de superação do colonialismo, que está articulado aos processos das lutas anticoloniais constituintes do processo de emancipação política das antigas colônias do julgo dos Estados europeus. E "decolonialidade" é um termo elaborado por um grupo de intelectuais estudiosos da modernidade/colonialidade nos anos 2000 que trazem para o contexto da América Latina a discussão pós-colonial; diz respeito à ideia de superar a colonialidade que continua exercendo influência sobre os dias atuais em um padrão de poder. Alguns dos autores que são referência nessa discussão são Walsh (2009), Colaço (2012), Castilho (2013), Martins (2014).
} 
intervenção para a formação de professores(as) - um projeto abancado nas experiências étnico-raciais e culturais dos afrodescendentes no Brasil -, compreendemos a importância de levar em consideração os argumentos de Gomes e Silva (201 1), que enfatizam que o trabalho com a diversidade é

uma competência político-pedagógica a ser adquirida pelos profissionais da educação nos seus processos formadores, influenciando de maneira positiva a relação desses sujeitos com os outros tanto na escola quanto na vida cotidiana (GOMES; SILVA, 2011, p. 23-24).

Além disso, Carrara, Carvalho e Lima (2010, p. 9) ressaltam que, no mundo contemporâneo, um grande desafio tem se constituído na "formação de pessoas que articulem diferentes saberes, de modo que assumam posturas comprometidas social, ética e politicamente". Ademais, as autoras pontuam que o maior desafio da educação "passa a ser propiciar situações de aprendizagem que interconectem diferentes áreas do saber e coloquem as pessoas em contato com manifestações e produções culturais diversas" (CARRARA; CARVALHO; LIMA, 2010, p. 09).

A partir de uma perspectiva intercultural, Candau $(2013$, p. 23) enfatiza a emergência de "uma educação para o reconhecimento do 'outro', para o diálogo entre os diferentes grupos sociais e culturais". É um modelo de educação que deve favorecer

a negociação cultural, que enfrenta os conflitos provocados pela assimetria de poder entre os diferentes grupos socioculturais nas nossas sociedades e é capaz de favorecer a construção de um projeto comum, pelo qual as diferenças sejam dialeticamente incluídas" (CANDAU, 2013, p. 23).

A autora destaca algumas propostas fundamentais quanto às práticas pedagógicas:

[1] Reconhecer nossas identidades culturais

[...] proporcionar espaços que favoreçam a tomada de consciência da construção da nossa própria identidade cultural, no plano pessoal, situando-a em relação com os processos socioculturais do contexto em que vivemos e da 
história do nosso país [...] (CANDAU, 2013, p. 25-26, grifos da autora).

[2] Desvelar o daltonismo cultural presente no cotidiano escola [...] [uma postura na escola] que favorece o caráter monocultural da cultura escolar, e que tem implicações muito negativas para a prática educativa; o daltonismo cultural não reconhece as diferenças étnicas, de gênero, de diversas origens regionais e comunitárias ou não as coloca em evidência na sala de aula [...] (CANDAU, 2013, p. 27, grifos da autora).

[3] Identificar nossas representações dos "outros"

[...] [as] representações que construímos dos "outros", daqueles que consideramos diferentes. As relações entre "nós" e os "outros" estão carregadas de estereótipos e ambiguidade [...] (CANDAU, 2013, p. 28, grifos da autora).

[4] Conceber a prática pedagógica como um processo de negociação cultural

[...] [trabalhar as] práticas educativas cotidianas [...] como processos de negociação cultural (CANDAU, 2013, p. 32, grifos da autora).

Trabalhar com a educação para as relações étnico-raciais nos leva a pensar e discutir uma proposta de educação antirracista (mas também antissexista, anti-homofóbica e antitransfóbica). Tal proposta nos remete ao que tem sido denominado de "agendas interculturais", que Miranda e Rosa (2014, p.140) definiram como "aquelas que acolhem a perspectiva de trabalhar política e pedagogicamente, valorizando as diferenças, que consideram a pluralidade de sujeitos e que indagam sobre os processos de ensinar-aprender".

Os argumentos das autoras demonstram que trabalhar sob a perspectiva de uma educação antirracista e das agendas interculturais nos permite ter clareza sobre os obstáculos advindos da nossa formação colonial perversa, que desvaloriza a pluralidade cultural e étnico-racial existente no país e impõe um currículo monocultural. As autoras sugerem que o caminho para essas transformações na educação está na "cooperação entre escola e universidade públicas, são conversas e recomposições didáticas e epistêmicas" (MIRANDA; ROSA, 2014, p. 140). É valorizar as "experiências docentes" e, a partir desse processo, promover um reposicionamento diante 
de conhecimentos instituídos como verdades e histórias únicas (MIRANDA; ROSA, 2014, p. 140). A história da humanidade é diversa e não pode ser confinada a modelos universalizantes e monoculturais. Portanto, é preciso estimular o "exercício ético-político", descolonizar os modos de ensinar e aprender - de apreender conhecimento - e trabalhar e desenvolver "outras dinamizações para os currículos praticados com os(as) estudantes" (MIRANDA; ROSA, 2014, p. 140).

As autoras propõem ainda que devemos nos orientar por um ideário de "justiça curricular", e atuar nessa perspectiva significa criar espaços e oportunidades para propiciar "experiências que lidem com outras formas de existir e de (re)existir a partir das práticas curriculares" (MIRANDA; ROSA, 2014 , p. 141).

É desse lugar que apresentamos, a seguir, dois relatos - embora não exaustivos, dada a exiguidade de espaço de um artigo - de experiências nas quais raça e gênero tomam lugar de proeminência para auxiliar na formação de futuras(os) profissionais da Educação, realizadas nos cursos de Pedagogia da UERJ e de Licenciatura em Educação do Campo da UFRRJ.

\section{Descolonização dos saberes em projetos de educação antirracista}

O termo racismo apareceu no período compreendido entre as duas guerras para se impor à linguagem corrente das sociedades ocidentais, e em todo o planeta no pós-guerra. Mas se a palavra é recente (seu ingresso no Dicionário Larousse data de 1932), as ideias e as práticas às quais ela remete são antigas e não procedem somente da experiência ocidental. É tentador falar de racismo sem temer o anacronismo a propósito dos antigos gregos, para os quais os bárbaros, aqueles que estavam fora da polis, eram seres humanos, com certeza, mas singularmente inferiores; ou ainda relembrar a densidade do racismo em certas sociedades asiáticas. $O$ fenômeno é com certeza anterior ao seu conceito, ou pelo menos à sua denominação (WIEVIORKA, 2007, p. 27).

O debate e os estudos sobre as relações raciais no Brasil - como os que subsidiam ambos os grupos aqui analisados - podem ser iniciados com alguma reflexão teórica sobre a construção social da raça e do racismo, 
uma vez que, ainda nos tempos hodiernos, o tema suscita altercações acaloradas tanto no âmbito acadêmico como na sociedade em geral. Nesse caso, podemos incluir a Educação e suas construções teóricas.

Diversos são os caminhos que podemos tomar para subsidiar as discussões sobre a questão racial, cotidianamente negada, que impacta as populações afrodescendentes. A citação em epígrafe nos conduz a entender que, antes mesmo que o fenômeno do racismo fosse nomeado, sua existência já era percebida no Brasil (e nas diversas regiões da diáspora africana), e essa compreensão antecede o reconhecimento pelo governo brasileiro. Tanto no Brasil como em outras partes do mundo, os movimentos negros já denunciavam e combatiam o racismo por meio de seus inúmeros projetos e ações.

Pereira (2013) nos lembra que o Estado-nação brasileiro já nasce a partir de uma construção de raça: o ideário de embranquecimento está presente desde os primórdios da nação. Surge então a imigração europeia como a desejada solução. Assim, teríamos - acreditava-se naquele período - um país desenvolvido socialmente com a chegada de um contingente massivo de povos brancos vindos da Europa.

A tensão sobre o ideal de superioridade e inferioridade racial é sentida e testemunhada nas salas de aula ou nos intervalos das aulas, seja na educação básica, seja no ensino superior. Alunos brancos - ou que assim se consideram - comportam-se de forma preconceituosa e discriminam seus pares não brancos, em especial os negros, por meio de agressões e insultos físicos e verbais, respaldados pela ideia de inferioridade destes últimos. Fatos dessa natureza, e ainda mais graves, ocorrem sem que professores e autoridades educacionais saibam como interferir diretamente contra tais eventos. Assim, esta é uma reflexão teórica e prática que deve ser inserida nos currículos e formações dos futuros profissionais da área.

Perante esse quadro de acontecimentos racistas no âmbito educacional, o projeto almeja promover, entre professoras(es) e estudantes universitárias(os) e professoras(es) da educação básica, formação em Educação para as Relações Étnico-Raciais e de Gênero. No caso do NEAB- 
UERJ, o relato se deterá exclusivamente sobre o projeto Mulheres Negras, Gênero, Família e Relações Étnico-Raciais: levantamento bibliográfico, documental e análise, desenvolvido no âmbito do núcleo. O projeto busca, desse modo, contribuir para a elaboração de novos e alternativos modelos teórico-metodológicos no campo de estudos das relações étnico-raciais e de gênero em educação, além de disseminar a produção de conhecimento e saberes sobre os afrodescendentes. A experiência relatada aqui diz respeito à atividade de extensão desenvolvida para professoras(es) de educação básica, a qual se constitui em um dos produtos do projeto de pesquisa organizado para beneficiar escolas e colégios localizados no Estado do Rio de Janeiro. O trabalho desenvolvido aborda:

a) a importância do reconhecimento e ressignificação das populações africanas e da diáspora africana como protagonistas de suas civilizações, bem como das histórias e culturas africana e afro-brasileira como legados importantes para o Brasil;

b) a desconstrução de estereótipos, preconceitos, discriminações e informações equivocadas sobre a África e suas populações na formação da sociedade brasileira;

c) a importância de oferecer às(aos) professoras(es) uma compreensão adequada sobre a influência dos africanos e de seus descendentes na história da formação da sociedade brasileira;

d) a importância de a escola criar espaços que assegurem à comunidade escolar um ambiente educacional que promova a construção de uma imagem positiva dos afrodescendentes como sujeitos históricos, bem como de meninas, jovens e mulheres negras na sociedade brasileira e, em especial, na escola. 
Nosso intuito no grupo de extensão N'BLAC é que este se torne um veículo capaz de ampliar informações, discussões e reflexões no âmbito da educação e dos direitos humanos, procurando estabelecer um diálogo para além dos limites dos campi universitários, propiciando intercâmbio, divulgação e difusão do conhecimento e da produção científica no combate ao racismo e ao sexismo. Almejamos, portanto:

a) formar (1) novas lideranças nos estudos e nas lutas antirracistas e antissexistas e (2) cidadãos e cidadãs, nas searas acadêmicas e profissionais, que se preocupem com os direitos humanos;

b) constituir - entre os nossos discentes - um corpo de experts que estejam capacitados técnica, teórica e metodologicamente para ministrar aulas, palestras e oficinas na comunidade em geral, assim como apresentar trabalhos em congressos, sobre as questões relativas ao antirracismo, ao antissexismo e aos direitos humanos;

c) contribuir para a formação de pesquisadores nos três níveis de formação acadêmica: graduação, mestrado e doutorado, consolidando assim um corpo de cidadãs e cidadãos de alta capacitação crítica e propositiva para a sociedade.

\section{A constituição de ambos os núcleos}

O Núcleo de Estudos Afro-Brasileiros da Universidade do Estado do Rio de Janeiro (NEAB-UERJ) se constituiu através do extinto Coletivo de Professores Negros da UERJ, tendo como objetivo desenvolver atividades de ensino, extensão e pesquisa ${ }^{5}$. Desde 2003, o núcleo tem oferecido cursos de extensão, organizado eventos e servido como campo de estágio discente, de produção de pesquisa e conhecimento e como fonte de referências bibliográficas e material didático voltados para a questão étnico-racial no

5 O núcleo atualmente é composto pelos docentes Maria Alice Rezende, Washington Dener, Ana Paula Alves Ribeiro, Rafael dos Santos, Cláudio de Carvalho Silveira, Sônia Beatriz dos Santos e llaina Damaceno Pereira. 
Brasil. Suas atividades têm sido financiadas por órgãos federais e agências como a Fundação Carlos Chagas Filho de Amparo à Pesquisa do Estado do Rio de Janeiro (FAPERJ) e o Fundo Nacional de Desenvolvimento da Educação (FNDE). O núcleo está conectado em rede nacional através do Consórcio de NEABs (CONNEABS).

Desse modo, podemos observar que o NEAB-UERJ tem, desde 2003, fomentado na Universidade do Estado do Rio de Janeiro espaços e práticas acadêmicas para a formação de estudantes e docentes em relações étnico-raciais. E é nesse contexto de realizações que se encaixa minha proposta de palestras-oficinas em educação para as relações étnico-raciais e de gênero; ela é parte das atividades desenvolvidas pelo projeto de pesquisa Mulheres Negras, Gênero, Família e Relações Étnico-Raciais: levantamento bibliográfico, documental e análise, que é financiado com recursos da FAPERJ. A proposta tem como objetivo identificar, analisar, documentar e disseminar literatura, documentários e filmes que abordem e/ou analisem as condições de vida, as práticas sociais, culturais e políticas, bem como as histórias, tradições, memórias e o pensamento das mulheres e das famílias negras, com foco especial nas produções que evidenciam realidades e questões associadas a educação, saúde e moradia.

Por seu turno, o Núcleo Brasileiro, Latino Americano e Caribenho de Estudos em Relações Raciais, Gênero e Movimentos Sociais (N'BLAC) tem uma história anterior à sua chegada à Universidade Federal Rural do Rio de Janeiro (UFRRJ). Registrado no Conselho Nacional de Desenvolvimento Científico e Tecnológico (CNPq) em 2007, o núcleo iniciou-se um ano antes, em 2006, na Universidade Federal do Ceará (UFC), sob a coordenação da Prof.a Dra. Joselina da Silva - que ali atuava como professora adjunta - e outros colaboradores. Em 2015, com a chegada à UFRRJ, para atuar no curso de Licenciatura em Educação do Campo, a referida docente o transformou num projeto de extensão, contando com a parceria de outros docentes.

O núcleo se voltou para atender às pessoas que já contam com formação universitária no âmbito das Ciências Sociais e àquelas que 
queiram aprender, refletir e debater sobre o assunto. Por ser aberto a toda a comunidade, busca produzir e difundir estudos e pesquisas por meio dos encontros e palestras que realiza. No grupo são destacadas abordagens que visam observar criticamente as interações entre relações étnico-raciais, gênero, educação e direitos humanos. Temos lido e debatido uma literatura acadêmica específica sobre as questões raciais, de gênero e dos movimentos sociais (com ênfase no movimento antirracista e no movimento feminista).

O lançamento do N'BLAC na nova instituição de ensino superior (IES) ocorreu em agosto de 2015 com a mesa-redonda intitulada "Os estudos, pesquisas e ações sobre África e cultura afro-brasileira: análise crítica", no campus Seropédica, da UFRRJ. Na ocasião, foram nossos palestrantes os seguintes professores: Glória Alves, (FEBEF/UERJ), Otair Fernandes de Oliveira (IM/UFRRJ), Luiz Fernandes de Oliveira (LEC/UFRRJ) e Amauri Mendes Pereira (DTPE/UFRRJ); a mesa foi coordenada pela Profa. Joselina da Silva (LEC/UFRRJ). Tratava-se da inauguração de nosso grupo, no âmbito do curso de Licenciatura em Educação do Campo.

Os encontros do grupo de estudos acontecem semanalmente no Instituto de Educação (IE) da UFRRJ. Por ser uma atividade frequentada pela maioria dos discentes do curso de Educação do Campo - onde a alternância é aplicada -, desenvolvemos atividades externas nesses períodos. É quando damos sequência à nossa itinerância, atendendo a convites de organizações de movimentos sociais e escolas para proferirmos palestras e/ou ministrarmos aulas ou oficinas sobre relações raciais e de gênero (com ênfase nos direitos e no movimento de mulheres negras).

Desde então, temos nos reunido semanalmente, atendendo ao calendário semestral da universidade. Como metodologia, fazemos uso de conhecimentos científicos utilizando livros, revistas, jornais, programas de televisão, filmes e redes sociais, entre outros, como materiais didáticos. Palestrantes também são convidados a contribuir com as reflexões, permitindo um maior aprofundamento das questões abordadas. Temos como meta a formação de novas lideranças nos estudos e nas lutas 
antirracistas e antissexistas, contribuindo com a formação de novos cidadãos e cidadãs que incluem em seu fazer teórico, acadêmico e profissional a percepção e a preocupação com os direitos humanos.

\section{Escolhas metodológicas visando influenciar currículos decolonizados}

É evidente que o currículo escolar, enquanto produto da ação humana, não se encontra imune aos interesses sociais, históricos e geograficamente situados. Seu entendimento sob essa perspectiva implica compreender, ao mesmo tempo, que as finalidades da educação escolar também estão implicadas por esses mesmos interesses, de modo que as diferentes teorias de currículo efetuam não somente deslocamentos importantes na maneira como se concebe o currículo nas diferentes épocas, assim como, igualmente, nas finalidades projetadas pra a educação (COSTA, 2012, p. 288).

O terceiro capítulo da Declaração e Programa de Ação da Conferência de Durban (2001) se refere às medidas de prevenção, educação e proteção visando à erradicação do racismo, da discriminação racial, da xenofobia e das formas correlatas de intolerância nos âmbitos nacional, regional e internacional. No parágrafo 74 deste capítulo, na subalínea 1 da alínea b, consta: "Desenvolvimento de materiais didáticos que ensinem aos jovens a importância da tolerância e do respeito" (CONFERÊNCIA..., 2001, p. 57). São princípios que podem iluminar e potencializar diversas ações nessa direção.

Assim, o projeto Mulheres Negras, Gênero, Família e Relações ÉtnicoRaciais: levantamento bibliográfico, documental e análise tem como alguns de seus produtos: levantamento bibliográfico, cobrindo literatura, documentários e filmes; discussões acerca da temática "Mulheres negras, gênero, família e relações étnico-raciais"; e a formação de um acervo bibliográfico e documental no núcleo sobre essa temática. Nesse sentido, espera-se que as experiências adquiridas pela equipe do projeto, bem como os materiais bibliográficos e documentais coletados, possam auxiliar na construção de ferramentas teórico-metodológicas e educativas e constituirse em fonte de pesquisa sobre as memórias, histórias, práticas sociais, 
culturais e políticas das mulheres e famílias negras no Brasil e em outras regiões da diáspora africana. Há aspectos desse projeto de pesquisa que consideramos muito positivos. Um deles é a oportunidade de formar um acervo bibliográfico e documental de publicações sobre os temas: mulheres negras, família negra, relações étnico-raciais e gênero. Estes são tópicos que tendem a ser esquecidos ou subutilizados nas bibliotecas das universidades públicas.

Nosso público - em ambos os NEABs - é semanalmente exposto aos diversos ângulos das temáticas com as quais trabalhamos (relações raciais e de gênero e direitos humanos) através da utilização de variados materiais didáticos: textos acadêmicos, artigos publicados em livros, revistas, jornais, filmes e vídeos, recursos que empregamos em leituras e debates. Além disso, reconhecemos a importância de nos beneficiarmos das intervenções de palestrantes - acadêmicos ou ativistas - que são convidados a contribuir com nosso aprofundamento crítico nos temas que nos balizam. Trata-se, portanto, de uma formação crítica que se renova e amplia a cada novo encontro. Assim, além de realizarmos encontros abertos e divulgados ao público em geral, bem como a toda a comunidade universitária, buscamos parcerias para cumprirmos o compromisso de atingir a comunidade também através da itinerância. As atividades já realizadas, no âmbito das instituições de ensino superior (IES), ganham expressão em outros ambientes, tais como escolas, movimentos sociais e outras IES que se interessem em estabelecer parcerias conosco. Nesse sentido, a metodologia que adotamos inclui organização de painéis, condução de oficinas, grupos de estudos, mesasredondas, visitas de intercâmbio e oficinas.

Seguindo na mesma direção, criamos - no âmbito do N'BLAC da UFRRJ - o minicurso O Pensamento de/por Mulheres Negras com o objetivo de apresentar e elaborar as reflexões de mulheres negras brasileiras, latinoamericanas e estadunidenses que produziram em diferentes tempos sóciohistóricos. Desejávamos contribuir com a ampliação de referenciais teóricos na área dos estudos de gênero e relações étnico-raciais. Portanto, trouxemos para as discussões elaborações diversas sobre os escritos de Pedrina de 
Deus, Virgínia Leone Bicudo, bell hooks, Lélia Gonzales, Ochi Curriel, Isabella Baumfree (Sojourner Truth), Oyeronke Oyewumi, Zora Neale Hurston e Carolina Maria de Jesus ${ }^{6}$. Entendemos e reconhecemos a grande contribuição do movimento social, notadamente o de mulheres negras, para a construção dessa epistemologia, pois elas trazem reflexões e denúncias acerca das formas de racismo e sexismo vigentes em nossas sociedades. Tal entendimento nos levou a inserir uma mesa-redonda com a participação de duas ativistas da atual safra de militantes baseadas na cidade do Rio de Janeiro ${ }^{7}$. Posteriormente o minicurso em tela foi transformado num livro homônimo, composto por textos analíticos elaborados pelas professoras convidadas e por uma entrevista com uma das ativistas do movimento de mulheres negras brasileiras ${ }^{8}$.

Experienciando palestras e palestras oficinas

Nilma Lino Gomes (2005) chama atenção para o fato de que educadores serão capazes de identificar e entender os meandros e especificidades do racismo presentes na sociedade brasileira se forem amparados por discussões e reflexões conceituais e teóricas sobre o tema. Dessa forma, poderão desvelar o racismo presente no cotidiano escolar. Se concordamos com a autora, temos então que esse é um assunto que deve integrar os estudos realizados durante o período de formação dos futuros docentes.

Paralelamente, a autora informa que tais leituras e discussões teóricas serão efetivas apenas se, ao seu lado e na mesma medida, ações práticas forem desenvolvidas. Nilma Gomes (2005) propõe a constituição de experiências em que professores em fase de formação sejam expostos às

\footnotetext{
6 As aulas semanais - referentes ao pensamento de cada uma dessas autoras - foram ministradas pelas seguintes professoras doutoras afro-brasileiras: Thula Rafaela de Oliveira Pires (PUC/RJ), Jaqueline Gomes de Jesus (IFRJ), Rosália Lemos (IFRJ), Cláudia Miranda (UNIRIO), Sônia Beatriz dos Santos (UERJ), Fernanda Felisberto (UFRRJ) e Joselina da Silva (UFRRJ).

7 Foram convidadas as ativistas Clátia Regina Vieira (Fórum Estadual de Mulheres Negras) e Samira Reis Marques da Silva (Hub das Pretas), as quais compuseram a mesa-redonda intitulada "Mulheres negras: nossas lutas e pensamentos atuais".

8 Cf. Silva (2018).
}

Revista Exitus, Santarém/PA, Vol. 10, p. 01-26, e020072, 2020. 
vivências e análises que os conduzam a construir intervenções pedagógicas. O antirracismo e as culturas negras devem ser o cerne dessas atividades de aprendizagem. A autora sugere ainda a inserção de debates sobre temas diversos, tais como "a influência da mídia, a religião, a cultura, a estética, a corporeidade, a música, a arte, os movimentos culturais, na perspectiva afrobrasileira" (GOMES, 2005, p. 151). Embora o texto volte-se para o fazer no âmbito escolar, entendemos que professoras(es) serão capazes de promover atividades, no desempenho de sua função docente, se tiverem sido expostas(os) a elas durante sua formação. É desse lugar que podemos situar as experiências aqui compartilhadas.

No projeto Mulheres Negras, Gênero, Família e Relações Étnico-Raciais: levantamento bibliográfico, documental e análise, compreendemos que a proposta de palestras-oficinas representa um esforço em contribuir para a identificação e disseminação de literaturas infanto-juvenis, bem como para o fomento à produção de materiais didáticos novos e alternativos, garantindo e ampliando assim o acesso de professoras(es) que atuam na educação infantil e no ensino fundamental l, de pesquisadoras(es) e estudantes a esse acervo.

A proposta tem como objetivo geral promover, para professoras(es) da educação infantil e do ensino fundamental I, formação em Educação para as Relações Étnico-Raciais e de Gênero, com foco na importância da preservação, documentação e disseminação das práticas sociais, culturais e políticas, das histórias, tradições e memórias das mulheres negras e da população afro-brasileira em geral, sobretudo daqueles aspectos que evidenciam realidades e questões associadas à educação. No que se refere aos objetivos específicos, almejamos:

a) promover o conhecimento da Lei $n^{\circ}$ 10.639/2003 e das Diretrizes Curriculares Nacionais para a Educação das Relações ÉtnicoRaciais e para o Ensino de História e Cultura Afro-Brasileira e Africana (BRASIL, 2004); 
b) trabalhar com as(os) professoras(es) a relevância do ensino de história e cultura afro-brasileira e africana nas escolas;

c) incentivar professoras(es) que atuam na educação infantil (EDI) e no ensino fundamental I a desenvolverem, em sala de aula e em outros espaços da escola, atividades com livros paradidáticos sobre educação para as relações étnico-raciais, em especial promovendo entre as(os) alunas(os) aspectos como autoestima e representatividade para reforçar a importância da presença e das contribuições dos povos africanos e afro-brasileiros no mundo;

d) trabalhar com as(os) professoras(es) a importância da conscientização sobre situações de vulnerabilidade e violência que meninas, jovens e mulheres negras podem vivenciar na escola.

\section{Formação docente e discente: uma proposta de novas epistemologias}

Nós do NEAB-UERJ, em particular a partir do levantamento bibliográfico e das primeiras discussões em torno deste, percebemos a necessidade de criar estratégias de valorização das experiências e da produção de conhecimento de intelectuais e/ou pesquisadoras(es) negras(os) no espaço escolar e acadêmico. Foi a partir dessa constatação que a equipe do projeto - constituída de docentes e discentes da graduação do curso de Pedagogia da Faculdade de Educação da UERJ começou a elaborar uma proposta de atividades em sala de aula para auxiliar professores(as) a trabalharem com os livros paradidáticos sobre educação para as relações étnico-raciais e de gênero, tendo como base a Lei $n^{\circ}$ 10.639/2003 e as Diretrizes Curriculares Nacionais para a Educação das Relações Étnico-Raciais e para o Ensino de História e Cultura Afro-Brasileira e Africana.

No caso do N'BLAC, nosso público-alvo são discentes e docentes da UFRRJ e professores das redes pública (nos três níveis, municipal, estadual e 
federal) e privada. É de nosso interesse também atender às demandas dos movimentos sociais que se voltam à luta contra o sexismo e o racismo na sociedade brasileira. Semanalmente temos uma presença que varia de dez a cinquenta participantes, de acordo com o tema abordado ou a titulação do(a) palestrante. Nossos seminários, dentro e fora da universidade, tem recebido um público de quarenta a duzentas pessoas, a depender do local e interesse pelos temas discutidos. Pretendemos manter essa marca, que consideramos exitosa.

Outras atividades em nossas ações

Entendendo que a formação para esses temas deve ser continuada e abranger metodologias diversas, entre as várias atividades realizadas no âmbito da UERJ, consideramos fundamental a realização de três eventos:

a) OI Mini-Seminário NEAB - As Relações Étnico-Raciais na Educação: Perspectivas Políticas e Pedagógicas na Conjuntura Política Atual, realizado em 20 e 21 de junho de 2017, tendo como principal palestrante convidada a professora Petronilha Beatriz da Silva, da Universidade Federal de São Carlos (UFSCAR);

b) o II Mini-Seminário NEAB - Liberdade Religiosa no Brasil: Questões para a Educação, realizado em 7 e 8 de dezembro de 2017. O evento foi realizado na Faculdade de Educação da UERJ em parceria com o Observatório de Favelas. Foram organizadas duas mesas:

- (1) "Experiências socioespaciais da juventude de terreiro: estratégias de visibilidade para conquistar a liberdade religiosa", que teve como palestrantes convidados Maria Luiza e Giuliano Freitas, representantes da Juventude de Terreiro da Renafro; 
- (2) "Liberdade religiosa no Brasil: contextos territoriais e diferentes modos de enfrentar a intolerância", que teve como palestrante convidado Miguel Ferreira Neto, presidente da Associação Espírita de Umbanda São Miguel e integrante do Conselho Nacional de Política Cultural - Setorial de Patrimônio Imaterial do Ceará;

c) e o III Mini-Seminário NEAB ocorrido de 30 de julho a 07 de agosto, que teve como palestrante convidada a Prof. a Dra. Faye V. Harrison (do Departamento de Estudos Afro-Americanos e do Departamento de Antropologia da Universidade de Illinois em UrbanaChampaign). Foram realizadas quatro palestras:

- (1) "Blacks Lives Matter: mudanças na ordem moral dos EUA, a legitimidade do racismo branco e The New Charleston";

- (2) "Navegando sites não-científicos de teoria e prática dos vários 'sules' da antropologia";

- (3) "Desafios da ação política de mulheres negras: pensamento sociais, estratégias e ferramentas contemporâneas";

- (4) "O papel das mulheres negras no Brasil e nos EUA - como andamos?".

Outro momento referencial no N'BLAC foi em março de 2016, com o seminário Mulher se Lançando para o Mundo, no qual palestraram a Profa. Dra. Graciela Garcia, Darci da Penha (Coordenadora Nacional e Estadual dos APNs - Agentes de Pastoral Negros) e a Dra. Laura Astrolábio (advogada e militante feminista). Imediatamente procedemos à realização do minicurso de extensão intitulado RACISMO: Para uma Descolonização do Pensamento Social Brasileiro. Foi um trabalho que gerou bons frutos e parcerias 
significativas, além de ganho para as comunidades, já que o projeto também atendeu a diversos grupos. Tivemos um total de mais de cento e cinquenta inscrições, com representantes de diversas instituições, dos movimentos sociais e de secretarias de educação municipais do Estado do Rio de Janeiro. O curso abrigou diversas abordagens teóricas e metodológicas sobre ação afirmativa, gênero, educação, políticas públicas, comunidades quilombolas, movimentos sociais, subalternidades, direitos humanos e história e cultura afro-brasileiras.

Tivemos também uma mesa de debates, com um grupo de estudantes oriundos de países africanos - Angola, Cabo Verde e Guiné Bissau integrantes de diferentes cursos da UFRRJ, sobre o seguinte tema: "Dialogando com a África e Diáspora". Encerramos o semestre com a apresentação musical do Grupo Vissungo, criado no Rio de Janeiro em 1975 e que até a atualidade produz música e cultura negra. No período letivo de 2017.1, iniciamos uma roda de conversa intitulada "A luta da mulher negra", atividade integrante da campanha 21 Dias de Ativismo Contra o Racismo organizada pelo movimento negro do Estado do Rio de Janeiro.

\section{Considerações finais}

Compreendemos que historicamente, ainda que observemos uma mudança positiva no cenário contemporâneo, persiste uma baixa valorização e utilização, por parte dos currículos escolares e acadêmicos, da produção intelectual existente que documenta e discute as histórias, tradições, memórias, práticas sociais, políticas e culturais dos afrodescendentes, em especial das mulheres, no Brasil. Consideramos que tal invisibilidade, nos espaços da educação básica e de fomento à pesquisa e ensino acadêmico, precisa ser revertida, pois representa uma grande perda no que tange à produção de conhecimento sobre as interseções entre as relações étnico-raciais e de gênero no Brasil e na diáspora africana num sentido mais amplo; e em especial para o campo das Ciências Sociais e Humanas. 
Entendemos que o processo de formação de novos pesquisadores, cidadãos e profissionais críticos, dá-se em dois formatos específicos, como constante formação recebida e ministrada. Ou seja, aprendemos não apenas quando estamos recebendo informações como também quando compartilhamos o aprendido com outros grupos em fases de formação menos avançada.

Portanto, nossas expectativas são, por um lado, promover a formação e a transformação de estudantes em professoras(es) e pesquisadoras(es) em educação no campo das Relações Étnico-Raciais e de Gênero e, por outro, oferecer a escolas de educação básica e suas(seus) professoras(es) uma experiência de formação fundamentada na educação para as relações étnico-raciais e de gênero pautada nos valores dos direitos humanos, de modo que tais docentes possam tornar-se agentes multiplicadores dessa perspectiva educacional. Por fim, almejamos que essa experiência auxilie a escola a compreender as contribuições da cultura e da história afrobrasileiras e africanas para $\circ$ Brasil e, num sentido mais amplo, para o mundo.

Desejamos atuar na rede de educação do Estado do Rio de Janeiro devido à diversidade e riqueza de seus contextos socioculturais e territoriais. Além disso, temos professoras(es) e alunas(os) de distintas regiões do estado atuando em duas frentes: na elaboração de palestras-oficinas vinculadas aos nossos projetos de pesquisa e de extensão; e em iniciativas autônomas organizadas por elas(eles) não apenas nas instituições educacionais em que atuam, como também nas comunidades em torno de suas unidades escolares. Tais atuações proporcionam, assim, vínculos e diálogos fundamentais para a organização da escola, particularmente em torno de uma proposta educacional antirracista e de valorização dos direitos humanos.

\section{Referências}

BRASIL. Conselho Nacional de Educação/Conselho Pleno/ DF. Resolução $n^{\circ}$ 1, de 17 de junho de 2004. Diretrizes Curriculares Nacionais para a Educação 


\section{das Relações Étnico-Raciais e para o Ensino de História e Cultura Afro-}

Brasileira e Africana. Brasília, DF, outubro, 2004. Disponível em:

<http://www.acaoeducativa.org.br/fdh/wp-content/uploads/2012/10/DCNs-Educacao-das-Relacoes-Etnico-Raciais.pdf>. Acesso em: 15 ago. 2015.

CANDAU, V. Multiculturalismo e educação: desafios para a prática pedagógica. In: MOREIRA, A.; CANDAU, V. (Org.). Multiculturalismo:

diferenças culturais e práticas pedagógicas. Petrópolis: Editora Vozes, 2013.

CARRARA, A. R.; CARVALHO, M. do C. B. de; LIMA, T. Cultura e educação na sociedade contemporânea. Cadernos Cenpec, São Paulo, SP, v. 5, n. 7, p. 611 , jan. 2010. ISSN 2237-9983. Disponível em:

<http://cadernos.cenpec.org.br/cadernos/index.php/cadernos/article/view/ 59/74>. Acesso em: 16 ago. 2016.

\section{CASTILHO, N. M. Pensamento descolonial e teoria crítica dos direitos}

humanos na América Latina: um diálogo a partir da obra de Joauín Herrera Flores. Dissertação. São Leopoldo: Universidade do Vale do Rio dos Sinos,

2013. Disponível em

<http://biblioteca.asav.org.br/vinculos/00000A/00000A6C.pdf>. Acesso em: 16 ago. 2016.

CONFERÊNCIA DE DURBAN. III Conferência Mundial contra o Racismo, a

Discriminação Racial, a Xenofobia e Formas Correlatas de Intolerância. 2001.

Durban. Declaração e Programa de Ação. Ministério da Cultura; Fundação

Cultural Palmares. Disponível em:

<http://www.unfpa.org.br/Arquivos/declaracao_durban.pdf>. Acesso em: 16 ago. 2016.

\section{COLAÇO, T. L. Novas perspectivas para a antropologia jurídica na América}

Latina: o direito e o pensamento decolonial. Florianópolis: Fundação Boiteux, 2012. Disponível em:

<https://repositorio.ufsc.br/bitstream/handle/123456789/99625/VD-Novas-

Perspectivas-FINAL-02-08-2012.pdf? sequence=1 \&isAllowed=y>. Acesso em: 16 ago. 2016.

COSTA, C. S. da. Currículo, relações étnico-raciais e os fundamentos teóricos da educação escolar. In: OLIVEIRA, l. de. (Org.). Relações raciais no contexto social, na educação e na saúde: Brasil, Cuba, Colômbia e África do Sul. 1. ed. Rio de Janeiro: Quartet, 2012. v. 1. 420p. p. 267-306.

GOMES, N. L. Educação e relações raciais: refletindo sobre algumas estratégias de atuação. In: MUNANGA, K. (Org.) Superando o racismo na escola. $2^{a}$ edição revisada. Brasília: Ministério da Educação, Secretaria de Educação Continuada, Alfabetização e Diversidade, 2005. p. 143-154. 
GOMES, N. L. O movimento negro educador: saberes construídos nas lutas por emancipação. Petrópolis, RJ: Vozes, 2017. 154 p.

GOMES, N. L.; SILVA, P. B. G. e. O desafio da diversidade. In: GOMES, N. L.; SILVA, P. B. G. e. Experiências étnico-culturais para a formação de professores. 3. ed. Coleção Cultura Negra e Identidade. Belo Horizonte: Autêntica Editora, 2011. p. 11-26.

LORDE, A. Sister outsider. Ten Speed Press, 1984 apud WEST, Cornel. Questão de raça. Tradução de Laura Teixeira Motta. São Paulo: Companhia das Letras, 1994.

MARQUES, E. P. de S.; SILVA, W. S. da S. (Org.). Educação, relações étnicoraciais e resistência: as experiências dos núcleos de estudos afro-brasileiros e indígenas no Brasil. Assis: Triunfal Gráfica e Editora, 2016.

MARTINS, P. H. O ensaio sobre o dom de Marcel Mauss: um texto pioneiro da crítica decolonial. Sociologias, Porto Alegre, v. 16, n. 36, p. 22-41, ago. 2014. Disponível em <http://www.scielo.br/pdf/soc/v16n36/1517-4522-soc-16-360022.pdf>. Acesso em: 16 ago. 2016.

MIRANDA, C.; ROSA, M. Igualdade étnico-racial na sala de aula: práticas interculturais em uma escola pública do município de Duque de Caxias-RJ. In: GOUVÊA, F. C. F.; OLIVEIRA, L. F. de; SALES, S. R. (Org.). Educação e relações étnico-raciais: entre diálogos contemporâneos e políticas públicas. 1. ed. Petrópolis, RJ: De Petrus et al.; Brasília, DF: CAPES, 2014.

PEREIRA, A. A. O mundo negro. Relações Raciais e a constituição do movimento negro contemporâneo no Brasil. Rio de Janeiro: Pallas/Faperj, 2013.

SILVA, J. da. (Org.). O pensamento de/por mulheres negras. Belo Horizonte: Nandyala, 2018.

WALSH, C. Interculturalidad, estado, sociedad: Iuchas (de)coloniales de nuestra época. Universidad Andina Simón Bolívar, Ediciones Abya-Yala: Quito, 2009. Disponível em:

<http://www.flacsoandes.edu.ec/interculturalidad/wpcontent/uploads/2012/01/Interculturalidad-estado-y-sociedad.pdf>. Acesso em: 16 ago. 2016.

WEST, C. Questão de raça/ Cornel West; tradução Laura Teixeira Motta. - São Paulo: Companhia das Letras, 1994.

WIEVIORKA, M. O racismo, uma introdução. São Paulo: Perspectiva, 2007. 
Recebido em: 04 de fevereiro de 2020 Aprovado em: 08 de maio de 2020 Publicado em: 28 de agosto de 2020

(c) (i) (5) 